IMMERGLUCK, L. Visual figural after-effects and field dependence. Psychonomic Science, 1966a, 4, 219-220.

IMMERGLUCK, L. Figural after-effects, rate of "figure-ground" reversal, and field dependence. Psychonomic Science, 1966b, 6, 45-46.

IMMERGLUCK, L. Further comments on "Is the figural aftereffect an aftereffect?" Psychological Bulletin, 1968, 70, 198-200.
PRESSEY, A. W., \& KOFFMAN, G. Figural aftereffects, illusions and the dimension of field dependence. Psychonomic Science, 1968, 10, 279-280.

\section{NOTE}

1. Supported by a U.S. Public Health Service research grant, $\mathrm{MH} \mathrm{14047-02.}$

\title{
Negative incentive contrast effects with verbal reinforcement ${ }^{1}$
}

\section{LAWRENCE WEINSTEIN ${ }^{2}$ and VINCENT MICHAEL COLUCCI, University of Maine, Portland, Maine 04103}

$A$ decrease in amount of reinforcement resulted in negative incentive contrast effects. This finding agrees with many studies involving animal Ss.

Negative incentive contrast effects are obtained when the performance of Ss exposed to a decrease in amount of reinforcement drops significantly below the performance of control Ss exposed to only the single lower reward magnitude. Investigations involving animal Ss have found that a decrease in incentive magnitude typically results in negative contrast effects. Crespi (1942) demonstrated that Ss exposed to a decrease in amount of reinforcement exhibited sudden decreases in performance that exceeded the levels of performance expected from the postshift magnitude of reinforcement. Negative incentive contrast effects have been observed in rats when using solid food (DiLollo \& Beez, 1966), and sucrose and saccharine (Weinstein, 1969). Little information is available concerning how human Ss respond to a decrease in amount of reinforcement. The present study attempted to determine how human Ss respond to a reduction in incentive magnitude.

\section{SUBJECTS}

The Ss were 15 male and 9 female undergraduate students enrolled in an introductory psychology course at the University of Maine, Portland. The Ss were assigned randomly to each of four equal groups.

\section{MATERIALS}

The materials consisted of a Kodak Carousel 750 slide projector, $5 \frac{1}{2} \mathrm{ft}$ from a $5 \%$-in. square piece of grey metal that served as a screen, $2 \times 1 \frac{1}{2}$ in. slides with digits typed on them (i.e., $776 \times 7$ ), and a stopwatch.

\section{PROCEDURE}

Each $S$ worked a sét of 15 mental multiplication problems. One answer or $30 \mathrm{sec}$ (whichever came first) was allowed for each problem, and there were $8 \mathrm{sec}$ between problems.

The problems were worked in four situations. Ss received no reinforcement after their answers $(\mathrm{N})$. Other Ss received a low (L) reward, one point, or a high $(\mathrm{H})$ reward, three points, after answering the 1st, 2nd, 4th, 6th, 9th, 10th, 11th, 12th, and 14th problems. And, finally, some individuals experienced a shift in reinforcement magnitude from high to low (S) after the 11 th problem.

The Ss who received $\mathrm{L}, \mathrm{H}$, or $\mathrm{S}$ were read the following instructions: "This is an experiment in abstract problem solving, the ability to rapidly work problems involving abstract reasoning. You will be given some problems to work. Each one consists of a three-digit number multiplied by a one-digit number. You are to mentally (without pencil and paper) multiply the numbers as quickly as you can and then tell me your answer. You will receive 0,1 , 2 , or 3 points after each answer. The closer

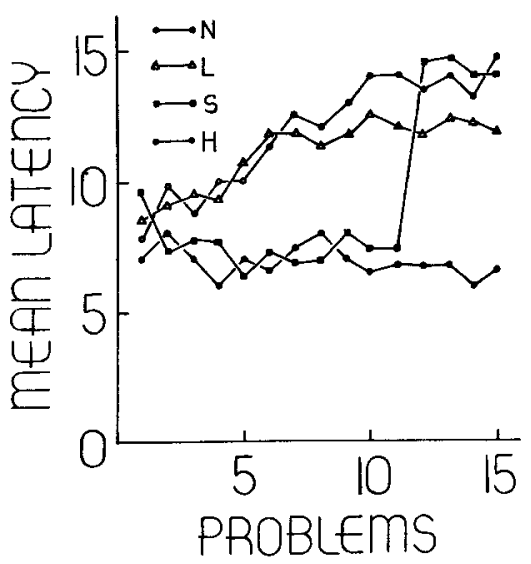

Fig. 1. Mean latency, in seconds, per problem. you are to being correct, the more points you will receive. You will be told perioddcally how you are doing."

In the instructions to the N Ss, reference to receiving points was omitted.

\section{RESULTS}

Latency means (the time between slide onset and the first response) were examined in the analysis of the results.

From Fig. 1, it appears that for Problems 1-11, the $S s$ in the $H$ condition took less time to answer than did the Ss in the $\mathrm{L}$ or $\mathrm{N}$ situations. It also seems that the Ss in the $\mathrm{N}$ condition took longer to answer than did the $\mathrm{Ss}$ in the $\mathrm{L}$ condition. The mean latency per problem from Problems 1-11 differed significantly among the four groups by analysis of variance $[F(3,20)=3.70, p<.05]$.

By Duncan's comparisons, the difference between $\mathrm{H}$ and $\mathrm{L}, \mathrm{H}$ and $\mathrm{N}, \mathrm{L}$ and $\mathrm{N}$ was each statistically significant $(p<.05)$, while the difference between $\mathrm{H}$ and $\mathrm{S}$ was not statistically reliable $(p>.05)$.

Figure 1 indicates that on Problem 12, S Ss abruptly increased their mean latency to a level below that of the $\mathrm{L}$ Ss (negative contrast effects). The mean latency per problem from Problems 12-15 differed significantly between the $S$ and $L$ Ss by an analysis of variance $[\mathrm{F}(1,10)=5.23$, $\mathrm{p}<.05]$.

\section{DISCUSSION}

The findings that for Problems 1-11 the $\mathrm{N}$ Ss took significantly more time to answer than any other Ss and that the H Ss took significantly less time to answer than the L Ss indicate that: (1) saying " 3 " or " 1 " after an answer served as a reinforcing event, and (2) two discriminably different levels of reinforcement were used.

The experiment demonstrated negative incentive contrast effects with a decrease in the amount of reinforcement.

This result agrees with many studies involving animal Ss (e.g., DiLollo \& Beez, 1966, Weinstein, 1969). It would appear that human Ss respond to a decrease in incentive magnitude as do many animal Ss.

\section{REFERENCES}

CRESPI, L. P. Quantitative variation in incentive and performance in the white rat. American Journal of Psychology, 1942, 55, 467-517.

DiLOLLO, V. D., \& BEEZ, V. Negative contrast effect as a function of magnitude of reward decrement. Psychonomic Science, 1966, 5, 99-100.

WEINSTEIN, L. Negative contrast effects with saccharine versus sucrose and continuous versus partial reinforcement. Paper presented at the meeting of the Eastern Psychological Association, Philadelphia, April 1969. NOTES

1. We thank Deborah Watkins for her help in planning the experiment.

2. Requests for reprints should be sent to Lawrence Weinstein, Department of Psychology, 96 Falmouth Street, University of Maine, Portland, Maine 04103. 